DOI: $10.12731 /$ wsd-2018-4-26-38

УДК 616.314-76; 616.314.14(075.8); 616.31

\title{
ОРТОПЕДИЧЕСКОЕ ЛЕЧЕНИЕ БОЛЬНЫХ С ЭНДОДОНТО-ПАРОДОНТАЛЬНЫМ СИНДРОМОМ
}

\author{
Мороз П.В., Проходная В.А., Биркина Ю.А., \\ Чистякова С.В.
}

В исследовании у 112 больных с эндопародонтальным синдромом в зависимости от наличия ортопедической реабилитачии (избирательное пришлифовывание и временное шинирование зубов) изучена клиническая эффективность лечения. Прирост зубодесневого прикрепления в течение 18 месяцев наблюдения был более выражен при включении в комплекс лечения временного шинирования зубов. У больных с эндопародонтальным синдромом со средней тяжестью поражения пародонта при наличии временного шинирования зубов коэффициент эффективности лечения был на 60\% выше, а при тяжелом поражении пародонта - на $35 \%$ выше. По результатам суммарной оченки динамики подвижности зубов, глубины пародонтальных карманов, величинь зубодесневого прикрепления, деструкиии альвеолярной кости, реактивности микрососудов и уровня микрочиркуляторного обеспечения тканей пародонта сформировано обоснование для рекомендации временного шинирования зубов с целью повышения эффективности лечения больных с эндопародонтальным синдромом.

Ключевые слова: эндопародонтальный синдром; ортопедическая реабилитаиия; пародонтит; клиническая эффективность лечения.

\section{CLINICO-FUNCTIONAL SUBSTANTIATION ORTHOPEDIC REHABILITATION OF PATIENTS WITH ENDOPARODONTAL SYNDROME}

\section{Moroz P.V., Prochodnaya V.A., Birkina Y.A., Chistyakova S.V.}

In a study in 112 patients with endoparodontal syndrome depending on the availability of orthopedic rehabilitation cal (selective grinding and temporary 
splinting of teeth) studied the clinical efficacy of the treatment. Increase the periodontal attachment during the 18 months of observation of follow-up was more than you-expression when incorporated into the complex treatment of temporary splinting of teeth. Patients with endoparodontal syndrome with an average severity of periodontal destruction in the presence of the temporary splinting of teeth-coe coefficient of efficiency of treatment was $60 \%$ higher, and in severe periodontal lesions - 35\% higher. As a result of the total evaluation of the dynamics of mobility of the teeth, the depth of periodontal pockets, the value of the periodontal attachment, destruction of the alveolar bone, and microvascular reactivity level of the microcirculatory ensure periodontal tissue formed the rationale for the recommendations of the interim shihning teeth in order to increase the effectiveness of treatment of patients with endoparodontal syndrome.

Keywords: endoparodontal syndrome; orthopedic rehabilitation; periodontal disease; the clinical efficacy of treatment.

\section{Введение}

Лечение больных с эндопародонтальным синдромом (ЭПС), когда в патологический процесс вовлечены эндодонт, периапикальный и маргинальный периодонт является сложной многоэтапной и комплексной задачей. Одной из задач стоматолога является ликвидация функциональной перегрузки, окклюзионной травмы или травматической окклюзии [5]. Патогенез развития травматической окклюзии при ЭПС видится в следующем. При ЭПС ввиду развития воспалительного процесса в периодонте происходит закисление среды, что вызывает частичную денатурацию фибриллярных нитей периодонтальных связок, распрямление нитей и ухудшение прикрепления зуба [9], повышение подвижности зубов, развитие травматической окклюзии [8]. Нагрузка на зубы при жевании становится нефункциональной, что ведет к остеопорозу [6]. При лечении хронического генерализованного пародонтита (ХГП) разработаны и успешно применяются методики временного шинирования зубов как один из этапов в комплексном лечении заболеваний пародонта [2]. При ЭПС упоминания о применении временного шинирования единичны [4]. Между тем, временное шинирование зубов при ЭПС показано по ряду обстоятельств. Верхушечный периодонт представляет собой не столько средство передачи механической нагрузки с зуба на альвеолярный гребень, сколько выполняет активную роль в моделировании костной ткани при наличии силового воздействия. При эндопародонтальном 
поражении сокращение площади апикального периодонта и снижении высоты альвеол при неизменной по силе нагрузке величина напряжения увеличивается, уменьшается адаптационно-компенсаторный потенциал опорного аппарата зуба. В ряде исследований постоянное жёсткое фиксирование подвижных зубов авторы считают нецелесообразным при наличии репаративной активности в периодонте [7, 10, 11]. Авторы советуют временное шинирование пораженных зубов при эндопародонтальных патологических процессах и травматической окклюзии, чтобы сохранить физиологическую подвижность, необходимую для ускорения заживления и восстановления пространственной ориентации и стабильного функционирования периодонтальных связок. Временное шинирование при ЭПС позволяет добиться лечебно-охранительного режима, поскольку снимает с тканей периодонта травмирующий фактор функции жевания и фактор подвижности зубов, максимально снимаются вертикальная и горизонтальная нагрузки [7]. С этой целью адекватно могут использоваться адгезивные волоконные шинирующие мостовидные протезы, обеспечивающие надежную фиксацию подвижных зубов с хорошими эстетическими качествами.

Целью настоящего исследования явилось повышение клинической эффективности лечения больных с ЭПС за счет включения в комплекс лечебных мероприятий ортопедической реабилитации адгезивными волоконными шинирующими мостовидными протезами.

\section{Материалы и методы исследования}

В клиническую группу были объединены 116 пациентов с ЭПС: наличием ХГП и одновременно с признаками хронического верхушечного периодонтита. Возраст больных в клинической группе колебался от 19 до 53 лет, в среднем составив 45,3 1 ,9 лет. Количество женщин было 51 (43,7\%), а мужчин -65 (56,3\%).

Все больные с ЭПС были разделены на две подгруппы в зависимости от наличия или отсутствия ортопедических мероприятий (избирательное пришлифовывание и временное шинирование зубов). 1 подгруппу составляли пациенты, у которых ортопедическая реабилитация входила в комплекс лечебных мероприятий и контролировалась пародонтологом. Во 2 подгруппу были объединены пациенты, у которых ортопедическая реабилитация не проводилась. Распределение больных ЭПС по подгруппам с учетом степени тяжести ХГП отражено в таблице 1 . 
Таблица 1 .

Распределение больных ЭПС 1 и 2 подгрупп с учетом степени тяжести ХГП

\begin{tabular}{|c|c|c|c|c|}
\hline \multirow{2}{*}{ Подгруппа } & \multicolumn{2}{|c|}{ Тяжесть ХГП у больных с ЭПС } & \multirow{2}{*}{ Всего } \\
\cline { 1 - 4 } & легкая & средняя & тяжелая & \\
\hline 1 & - & $45(54,9 \%)$ & $18(66,7 \%)$ & $63(54,5 \%)$ \\
\hline 2 & $6(100 \%)$ & $37(45,1 \%)$ & $10(33,3 \%)$ & $53(45,5 \%)$ \\
\hline Всего & $6(100 \%)$ & $82(100 \%)$ & $24(100 \%)$ & $116(100 \%)$ \\
\hline
\end{tabular}

Эффективность своевременной ортопедической реабилитации определяли путем сравнительного анализа динамики индексной оценки состояния и кровоснабжения тканей пародонта в двух подгруппах с учетом тяжести ХГП.

Для сравнительной оценки эффективности использования временного шинирования зубов при лечении ЭПС была использована методика «5х5», разработанная Белоусовым Н.Н. [1]. На пяти этапах наблюдения за больными оценивали состояние пародонта: 1 этап - через 2 недели лечения, 2 этап - через 1 месяц, 3 этап - через 3 месяца, 4 этап - через 12 месяцев, 5 этап - через 18 месяцев от начала лечения. Состояние пародонта оценивали по пяти показателям в баллах: 1) подвижность зубов; 2) восстановление зубодесневого прикрепления; 3) рентгенологическая картина; 4) состояние реактивности микрососудистого русла пародонта; 5) состояние кровоснабжения тканей пародонта. Балльная оценка проводилась в сравнении с показателями до лечения и между этапами.

Подвижность зубов оценивали по шкале Миллера по модификации Fleszar T.J. Восстановление зубодесневого прикрепления оценивали по динамике изменения величины потери зубодесневого прикрепления и глубины пародонтального кармана. При рентгенологическом исследовании по этапам анализировали резорбцию корней, расширение периодонтальной щели, наличие зубного камня, изменение альвеолярной кости, определяли индекс деструкции альвеолярной кости (индекс Фукса).

При изучении состояния реактивности микрососудистого русла пародонта из всех показателей лазерной допплеровской флоуметрии (ЛДФ), в соответствии с рекомендациями Е.К.Кречиной с соавт. (2016) было выбрано среднее арифметическое значение уровня микроциркуляции (М) [3]. При определении реактивности микрососудов вычисляли амплитуду снижения кровотока при холодовой пробе. Состояние кровоснабжения тканей пародонта оценивали по величине уровня микроциркуляции М в динамике. 
Для суммарной оценки влияния временного шинирования зубов на общий эффект лечения ЭПС, по методике Белоусова Н.Н. (2009) балльная оценка признаков проводилась именно в динамике в сравнении с показателями до лечения [1]. Поскольку у больных ЭПС с легкой степенью тяжести ХГП шинирование не проводили, то результаты этих пациентов в сравнительном аспекте не анализировали.

Статистический анализ результатов исследования проводился с помощью программы STATISTICA 7.0 (StatSoft Inc., США). В работе исследованные величины были представлены в виде выборочного среднего значения и стандартной ошибки средней величины. Достоверность различий средних величин независимых выборок оценивали с помощью непараметрического критерия Манна-Уитни ввиду отличия распределения показателей от нормального. Проверку на нормальность распределения оценивали с помощью критерия Колмогорова-Смирнова.

\section{Результаты}

Уровень зубодесневого прикрепления является основным показателем эффективности проводимого лечебного вмешательства при патологии пародонта. Уменьшение величины потери прикрепления в динамике у пациентов с ЭПС двух подгрупп отражало благоприятную динамику лечения в течение всего периода наблюдения (табл. 2).

Таблица 2 .

Динамика величины потери зубодесневого прикрепления (мм) у больных ЭПС с учетом наличия временного шинирования зубов и тяжести ХГП

\begin{tabular}{|c|c|c|c|c|c|c|c|}
\hline \multirow{2}{*}{$\begin{array}{c}\text { Тяжесть ХГП } \\
\text { при ЭПС }\end{array}$} & Подгруппа & Исходно & $\begin{array}{c}1 \\
\text { (ч3 2 } \\
\text { нед) }\end{array}$ & $\begin{array}{c}2 \\
\text { (ч3 1 } \\
\text { мсц) }\end{array}$ & $\begin{array}{c}3 \\
\text { (ч3 3 мсц) }\end{array}$ & $\begin{array}{c}4 \\
\text { (ч3 12 } \\
\text { мсц) }\end{array}$ & $\begin{array}{c}5 \\
\text { (чз 18 } \\
\text { мсц) }\end{array}$ \\
\hline \multirow{2}{*}{$\begin{array}{c}\text { Средняя } \\
(\mathrm{n}=82)\end{array}$} & $1(\mathrm{n}=45)$ & $7,1 \pm 0,5$ & - & - & $2,9 \pm 0,3^{*}$ & $2,3 \pm 0,2^{*}$ & $2,2 \pm 0,4^{*}$ \\
\cline { 2 - 9 } & $2(\mathrm{n}=37)$ & $7,2 \pm 0,6$ & - & - & $4,3 \pm 0,5^{*}$ & $3,5 \pm 0,3^{*}$ & $3,6 \pm 0,5^{*}$ \\
\hline \multicolumn{2}{|c|}{$\mathrm{p}_{1-2}$} & $>0,05$ & & & $<0,05$ & $<0,05$ & $<0,05$ \\
\hline \multirow{2}{*}{$\begin{array}{c}\text { Тяжелая } \\
(\mathrm{n}=24)\end{array}$} & $1(\mathrm{n}=16)$ & $8,2 \pm 0,4$ & - & - & $4,4 \pm 0,4^{*}$ & $3,6 \pm 0,2^{*}$ & $3,4 \pm 0,3^{*}$ \\
\cline { 2 - 9 } & $2(\mathrm{n}=8)$ & $8,3 \pm 0,7$ & - & - & $5,8 \pm 0,6^{*}$ & $5,5 \pm 0,4^{*}$ & $4,8 \pm 0,6^{*}$ \\
\hline \multicolumn{2}{|c|}{$\mathrm{p}_{1-2}$} & $>0,05$ & & & $<0,05$ & $<0,05$ & $<0,05$ \\
\hline
\end{tabular}

Примечание: * - достоверное отличие по сравнению с исходными результатами при $\mathrm{p}<0,05$

При средней степени тяжести ХГП и наличии временного шинирования зубов величина потери зубодесневого прикрепления через 3 мес. 
сократилась на $59 \%(\mathrm{p}<0,05)$ и составила $2,9 \pm 0,3$ мм и далее снизилась

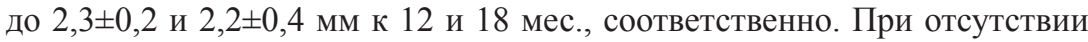
временной ортопедической реабилитации величина потери зубодесневого прикрепления через 3 мес. сократилась на $40 \%(\mathrm{p}<0,05)$ и составила

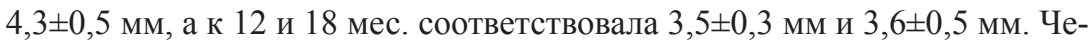
рез 3, 12 и 18 мес. от начала лечения в 1 подгруппе величина потери зубодесневого прикрепления по сравнению с исходным уровнем снизилась, соответственно, на $59 \%(\mathrm{p}<0,05), 68 \%(\mathrm{p}<0,05)$ и $69 \%(\mathrm{p}<0,05)$, а в подгруппе Б - на $40 \%(\mathrm{p}<0,05), 51 \%(\mathrm{p}<0,05)$ и $50 \%(\mathrm{p}<0,05)$.

При тяжелой степени тяжести ХГП через 3, 12 и 18 мес. в 1 подгруппе по сравнению со 2 подгруппой величина потери зубодесневого прикрепления была ниже, соответственно, на $24 \%$ ( $<<0,05), 35 \%(\mathrm{p}<0,05)$ и $29 \%$ $(\mathrm{p}<0,05)$, соответственно. Ограничение потери зубодесневого прикрепления в динамике наблюдения за больными ЭПС было наиболее эффективным в 1 подгруппе при средней степени тяжести ХГП.

Следовательно, прирост зубодесневого прикрепления, который является ключевым клиническим показателем эффективности лечения патологии пародонта, был более выражен при включении в комплекс лечения временного шинирования зубов. При наличии шинирования у больных ЭПС и тяжелой степенью тяжести ХГП индекс подвижности зубов был статистически значимо ниже во все периоды наблюдения как в раннем, так и отдаленном периодах. При отсутствии шинирования зубов достоверное снижение показателя произошло только через 3 мес. от начала лечения. При рентгенологическом исследовании после комплексного лечения, с включением временного шинирования зубов, через 6-12 месяцев прозрачность костной ткани уменьшилась, появился более четкий контур межкорневых перегородок, крупнопетлистость ее стала менее выраженной, что свидетельствует об увеличении плотности костной ткани. При тяжелой степени тяжести ХГП при рентгенологическом исследовании после комплексного лечения в обеих группах наблюдалась стабилизация деструктивных процессов в костной ткани альвеолярных отростков и частей, прекращалось образование новых очагов деструкции и костных карманов. Временное шинирование зубов при ЭПС благоприятно сказывалось на ограничении деструкции альвеолярной кости. Реактивность микрососудов по ходу наблюдения за больными снижалась во всех подгруппах. Но в 1 подгруппе как при средней, так и при тяжелой степени тяжести ХГП при наличии временного шинирования снижение амплитуды реакции микрососудов на холод было выражено в большей мере. Таким образом, у больных 1 подгруппы реактивность микрососудов, слу- 
жащая патогенетической основой для развития застойной гипермии, эффективно ограничивалась. У пациентов 1 подгруппы статистически значимое повышение кровотока на $25 \%(\mathrm{p}<0,05)$ наблюдалось уже через 1 мес. от начала лечения, а в подгруппе Б - только через 3 мес. (на 21\%). Повышение уровня кровотока в 1 подгруппе превышало по амплитуде изменение уровня микроциркуляции во 2 подгруппе. По результатам суммарной оценки динамики подвижности зубов, глубины пародонтальных карманов, величины зубодесневого прикрепления, деструкции альвеолярной кости, реактивности микрососудов и уровня микроциркуляторного обеспечения тканей пародонта был вычислен коэффициент эффективности лечения в подгруппах больных с учетом наличия временного шинирования зубов и тяжести ХГП, величины которого представлены в таблице 3.

Таблица 3.

Значения коэффициентов эффективности лечения у больных ЭПС с учетом наличия временного шинирования зубов и тяжести ХГП

\begin{tabular}{|c|c|c|}
\hline Тяжесть ХГП при ЭПС & Подгруппа & Коэффициент эффектив. лечения \\
\hline \multirow{2}{*}{ Средняя $(\mathrm{n}=82)$} & $1(n=45)$ & $0,64 \pm 0,08$ \\
\hline & $2(n=37)$ & $0,40 \pm 0,05$ \\
\hline \multicolumn{2}{|l|}{$p_{1-2}$} & $<0,05$ \\
\hline \multirow{2}{*}{ Тяжелая $(\mathrm{n}=24)$} & $1(\mathrm{n}=16)$ & $0,50 \pm 0,04$ \\
\hline & $2(\mathrm{n}=8)$ & $0,37 \pm 0,06$ \\
\hline \multicolumn{2}{|l|}{$p_{1}$} & $<0,05$ \\
\hline
\end{tabular}

У больных ЭПС со средней тяжестью ХГП при наличии временного шинирования зубов суммарный коэффициент эффективности лечения составил $0,64 \pm 0,08$ баллов, а при отсутствии ортопедической реабилитации был ниже $-0,40 \pm 0,05$ баллов. При тяжелой степени тяжести ХГП в 1 подгруппе итоговый коэффициент эффективности лечения составил $0,50 \pm 0,04$ баллов, а во 2 подгруппе $-0,37 \pm 0,06$ баллов.

При наличии временного шинирования зубов у больных ЭПС со средней тяжестью поражения пародонта коэффициент эффективности лечения был на $60 \%(\mathrm{p}<0,05)$ выше, а при тяжелом поражении пародонта - на $35 \%(p<0,05)$ выше. Сопряжение между эффективностью лечения ЭПС по результатам клинико-рентгенологического исследования и применением ортопедической реабилитации больных путем избирательного пришлифовывания зубов и их временного шинирования изучали методом построения таблиц сопряженности и расчета критерия согласия Пирсона. Статистическая матрица для анализа представлена в таблице 4. 
Таблица 4.

Оценка влияния временного шинирования зубов на клинико-рентгенологические результаты комплексного лечения у больных с ЭПС через 18 мес.

\begin{tabular}{|c|c|c|c|}
\hline \multirow{2}{*}{$\begin{array}{c}\text { Достижение клинико-рентгеноло- } \\
\text { гической реконвалес. }\end{array}$} & \multicolumn{2}{|c|}{ Временное шинирование зубов } & \multirow{2}{*}{ Всего } \\
\cline { 2 - 3 } & Присутствует & Отсутствует & \\
\hline Присутствует & $55(88,5 \%)$ & $36(68,6 \%)$ & 89 \\
\hline Отсутствует & $8(11,5 \%)$ & $17(31,4 \%)$ & 23 \\
\hline Всего & $63(100 \%)$ & $53(100 \%)$ & 116 \\
\hline$\chi^{2}, \mathrm{p}$ & \multicolumn{2}{|c|}{$\chi^{2}=5,57 ; \mathrm{p}=0,018$} \\
\hline Коэффициент контингенции & \multicolumn{3}{|c|}{0,22} \\
\hline
\end{tabular}

Критерий согласия Пирсона между эффективностью лечения больных ЭПС и наличием временного шинирования зубов составил 5,57, превышал критическую величину и его достоверность была статистически значимой $(\mathrm{p}=0,018)$, что позволило сформировать заключение о сопряжении двух процессов - успешности клинико-рентгенологической реконвалесценции у больных с ЭПС и своевременной ортопедической реабилитацией.

Таким образом, временное шинирование зубов оказывает благоприятное воздействие на эффективность лечения больных ЭПС: более быстрыми темпами и с большей выраженностью снижалась патологическая подвижность зубов, глубина пародонтальных карманов, эффективно ограничивалась потеря зубодесневого прикрепления, деструкция альвеолярной кости, улучшалось микроциркуляторное обеспечение тканей пародонта. Данное обстоятельство является обоснованием для рекомендации временного шинирования зубов для повышения эффективности лечения больных с ЭПС.

\section{Выводы}

1. При наличии временного шинирования зубов у больных ЭПС со средней и тяжелой степенью тяжести поражения пародонта коэффициент эффективности лечения был на $60 \%(\mathrm{p}<0,05)$ и $35 \%$ $(\mathrm{p}<0,05)$ выше по сравнению с больными, в комплекс лечения которых не входила ортопедическая реабилитация.

2. Для повышения эффективности лечения ЭПС рекомендуется в комплекс лечебных вмешательств включать временное шинирование зубов. 


\section{Список литературы}

1. Белоусов Н.Н. Определение эффективности шинирования зубов при тяжелых формах воспалительных заболеваний пародонта // Пародонтология. 2009. № 1. С. 8-10.

2. Журавлев В.А., Казакова А.В. Методы фиксации подвижных зубов при лечении хронического генерализованного пародонтита // Проблемы стоматологии. 2014. №2. С. 4-8.

3. Кречина Е.К., Зорина О.А., Молчанов А.М., Шилов А.М. Нарушения микроциркуляции в тканях пародонта у пациентов с хроническим генерализованным пародонтитом в сочетании с метаболическим синдромом // Стоматология. 2016. N 1. С. 27-30.

4. Мухамеджанова Л.Р. Оценка распространенности и структура эндодонто-пародонтальных поражений: значение в клинической практике // Клиническая стоматология. 2011. № 2. С. 99-101.

5. Маланьин И.В. Клиника, диагностика и лечение эндодонтических и пародонтологических патологий: Монография. Издательский дом «Плехановец». Краснодар, 2005. 436 с.

6. Митронин А.В. Оценка эффективности трансканального применения Коллапан-геля, содержащего антимикробные средства, в лечении деструктивных форм хронического периодонтита на основании данных молекулярно-генетических исследований / А.В. Митронин, В.Н. Царев // Труды IX съезда Стоматологической Ассоциации России. М., 2004. С. 166-169.

7. Мороз П.В. Эндодонтическое лечение в комплексной терапии эндопародонтального синдрома // Материалы XIII Всероссийской научно-практической конференции. М., 2004. С. 169-171.

8. Мороз П.В. Эндодонтическое лечение в комплексной терапии пародонтита / П.В. Мороз, Н.М. Гаджиев, С.Л. Кононенко // Главный врач Юга России. 2013. № 3 (34). С. 23.

9. Орехова Л.Ю. Влияние сочетанных поражений осложненного кариеса и воспалительных заболеваний пародонта на состояние зубочелюстной системы / Л.Ю. Орехова, Т.В. Кудрявцева, В.А. Осипова, А.А. Бармашева // Пародонтология. 2004. № 2(31). С. 8-14.

10. Ряховский А.Н. Влифяние механической нагрузки на ткани пародонта // Стоматология. 2010. №3. С. 72-75.

11. Силин А.В., Абрамова Н.Е., Леонова Е.В., Туманова С.А., Пастухова А.С. Диагностика и планирование эндо-пародонтальных поражений // Пародонтология. 2015. №3 (76) . С. 74-80.

12. Сорокина Н.В. Эндодонтические вмешательства у больных пародонтитом: автореф. дис. ...канд. мед. наук. Смоленск. 2007. 22 с. 
13. Harrington G.W., Steiner D.R. Periodontal-endodontic considerations // In: Walton R.E., Torabinejad M. Principles and practice of endodontics, 3rd edn. Philadelphia: W.B. Saunders Co. 2002, pp. 466-484.

14. Ingimarsson S., Von Arx T. A new splint technique in dental traumatology. // Schweiz Monatsschr Zahnmed. 2002. Vol.112. N12, pp. 1263-1273.

15. Kerns D.G., Glickman G.N. Endodontic and periodontal interrelationships. In: Cohen S and Hargreaves K.M., Eds. Pathways of the pulp, 9th Ed.St. Louis:. Mosby Inc. 2006, pp. 650-667.

16. Peeran S.W. Endo-Perio Lesions / S.W. Peeran, M. Thiruneervannan, K.A. Abdalla, M.H. Mugrabi // International journal of scientific \& technology research. 2013. Vol. 2. N 5, pp. 268-274.

17. Rotstein I. The endo-perio lesion: a critical appraisal of the disease condition / I. Rotstein, J.H. Simon // Endodontic Topics. 2006. N 13, pp. 34-56.

18. Rupf S., Kannengiesser S., Merte K., Pfister W., Sigusch B., Eschrich K. Comparison of profiles of key periodontal pathogens in the periodontium and endodontium // Endo Dent. Traumatol. 2000. Vol.16, pp. 269-275.

19. Von Arx T. Splinting of traumatized teeth with focus on adhesive techniques. // J. Calif. Dent. Ass. 2005. Vol.33. N5, pp. 409-414.

20. Von Arx T., Filippi A., Buser D. Splinting of traumatized teeth with a new device: TTS (Titanium Trauma Splint) // Dent. Traumatol. 2001. Vol.17. N4, pp. 180-184.

\section{References}

1. Belousov N.N. Parodontologiya. 2009. № 1, pp. 8-10.

2. Zhuravlev V.A., Kazakova A.V. Problemy stomatologii. 2014. №2, pp. 4-8.

3. Krechina E.K., Zorina O.A., Molchanov A.M., Shilov A.M. Stomatologiya. 2016. N 1, pp. 27-30.

4. Mukhamedzhanova L.R. Klinicheskaya stomatologiya. 2011. № 2, pp. 99-101.

5. Malan'in I.V. Klinika, diagnostika i lechenie endodonticheskikh i parodontologicheskikh patologiy [Clinic, diagnosis and treatment of endodontic and parodontological pathologies]. Izdatel'skiy dom «Plekhano-vets». Krasnodar, $2005.436 \mathrm{p}$

6. Mitronin A.V., Tsarev V.N. Trudy IX sezda Stomatologicheskoy Assotsiatsii Rossii [Proceedings of the IX Congress of the Stomatological Association of Russia]. M., 2004, pp. 166-169.

7. Moroz P.V. Materialy XIII Vserossiyskoy nauchno-prakticheskoy konferentsii [Materials of the XIII All-Russian Scientific and Practical Conference]. M., 2004, pp. 169-171. 
8. Moroz P.V., Gadzhiev N.M., Kononenko S.L. Glavnyy vrach Yuga Rossii. 2013. № 3 (34). P. 23.

9. Orekhova L.Yu., Kudryavtseva T.V., Osipova V.A., Barmasheva A.A. Parodontologiya. 2004. № 2(31). P. 8-14.

10. Ryakhovskiy A.N. Stomatologiya. 2010. №3, pp. 72-75.

11. Silin A.V., Abramova N.E., Leonova E.V., Tumanova S.A., Pastukhova A.S. Parodontologiya. 2015. №3 (76), pp. 74-80.

12. Sorokina N.V. Endodonticheskie vmeshatel'stva u bol'nykh parodontitom [Endodontic interventions in patients with parodontitis]. Smolensk. 2007. 22 p.

13. Harrington G.W., Steiner D.R. Periodontal-endodontic considerations // In: Walton R.E., Torabinejad M. Principles and practice of endodontics, 3rd edn. Philadelphia: W.B. Saunders Co. 2002, pp. 466-484.

14. Ingimarsson S., Von Arx T. A new splint technique in dental trauma-tology. Schweiz Monatsschr Zahnmed. 2002. Vol.112. N12, pp. 1263-1273.

15. Kerns D.G., Glickman G.N. Endodontic and periodontal interrelation-ships. In: Cohen S and Hargreaves K.M., Eds. Pathways of the pulp, 9th Ed.St. Louis: Mosby Inc. 2006, pp. 650-667.

16. Peeran S.W. Endo-Perio Lesions / S.W. Peeran, M. Thiruneervannan, K.A. Abdalla, M.H. Mugrabi. International journal of scientific \& technology research. 2013. Vol. 2. N 5, pp. 268-274.

17. Rotstein I. The endo-perio lesion: a critical appraisal of the disease condition / I. Rotstein, J.H. Simon. Endodontic Topics. 2006. N 13, pp. 34-56.

18. Rupf S., Kannengiesser S., Merte K., Pfister W., Sigusch B., Eschrich K. Comparison of profiles of key periodontal pathogens in the periodontium and endodontium. Endo Dent. Traumatol. 2000. Vol.16, pp. 269-275.

19. Von Arx T. Splinting of traumatized teeth with focus on adhesive tech-niques. J. Calif. Dent. Ass. 2005. Vol.33. N5, pp. 409-414.

20. Von Arx T., Filippi A., Buser D. Splinting of traumatized teeth with a new device: TTS (Titanium Trauma Splint). Dent. Traumatol. 2001. Vol.17. N4, pp. 180-184.

\section{ДАННЫЕ ОБ АВТОРАХ}

Мороз Павел Владиславович, к.м.н., доцент, заведующий кафедры стоматологии №1

Федеральное Государственное Бюджетное Образовательное Учреждение Высшего Образования «Ростовский Государственный Медииинский Университет» Министерства Здравоохранения Российской Федерации 
ул. Нахичеванский, 29, г. Ростов-на-Дону, 344022, Российская Федерачии sarmat-300@yandex.ru

Проходная Виктория Александровна, д.м.н. доцент, профессор кафедры стоматологии №1

Федеральное Государственное Бюджетное Образовательное Учреждение Выстего Образования «Ростовский Государственный Медицинский Университет» Министерства Здравоохранения Российской Федерации

ул. Нахичеванский, 29, г. Ростов-на-Дону, 344022, Российская Федерациии

ms.victoria111@mail.ru

Биркина Юлия Алексеевна, ассистент кафедры стоматологии №1 Федеральное Государственное Бюджетное Образовательное Учреждение Высшего Образования «Ростовский Государственный Медицинский Университет» Министерства Здравоохранения Российской Федерачии

ул. Нахичеванский, 29, г. Ростов-на-Дону, 344022, Российская Федерачии

birkinayuliya@mail.ru

Чистякова Софья Владимировна, ассистент кафедры стоматологии №1 Федеральное Государственное Бюджетное Образовательное Учреждение Высшего Образования «Ростовский Государственный Медииинский Университет» Министерства Здравоохранения Российской Федерачии

ул. Нахичеванский, 29, г. Ростов-на-Дону, 344022, Российская Федеращчи

sonya506@mail.ru

\section{DATA ABOUT THE AUTHORS}

Moroz Pavel Vladislavovich, CMS, Assistant Professor, Head of the Department of Stomatology №1

Rostov State Medical University

29, Nakhichevanskij Str., Rostov-on-Don, 344022, Russian Federation sarmat-300@yandex.ru 
Prokhodnaya Viktoriya Aleksandrovna, DMS, Assistant Professor, Professor of the Department of Stomatology №1

Rostov State Medical University

29, Nakhichevanskij Str., Rostov-on-Don, 344022, Russian Federation ms.victoria111@mail.ru

Birkina Yulia Alekseevna, CMS, Assistant of the Department of Stomatology №1

Rostov State Medical University

29, Nakhichevanskij Str., Rostov-on-Don, 344022, Russian Federation birkinayuliya@mail.ru

Chistyakova Sofia Vladimirovna, Assistant of the Department of Stomatology №1

Rostov State Medical University

29, Nakhichevanskij Str., Rostov-on-Don, 344022, Russian Federation sonya506@mail.ru

ORCID: 0000-0002-0742-3802

ResearcherID: U-4148-2017 